Tropical Journal of Pharmaceutical Research October 2011; 10 (5): 595-602

(C) Pharmacotherapy Group,

Faculty of Pharmacy, University of Benin

Benin City, 300001 Nigeria.

All rights reserved.

Available online at http://www.tjpr.org

Research Article

http://dx.doi.org/10.4314/tjpr.v10i5.8

\title{
Evaluation of the Hematological, Hypoglycemic, Hypolipidemic and Antioxidant Properties of Amaranthus Tricolor Leaf Extract in Rat
}

\author{
A Colaco e Clemente and PV Desai \\ Physiology Laboratory, Department of Zoology, Goa University, Goa, India
}

\begin{abstract}
Purpose: To investigate the effect of Amaranthus tricolor leaf extract on some biochemical parameters in diabetic and normal rats

Methods: A. tricolor aqueous extract was assayed for antioxidant properties using ferric reducing ability of plasma (FRAP) assay, 2,2-diphenyl-1-picrylhydrazyl (DPPH) assay and phosphomolybdenum assay. The effect of the leaf extract on serum glucose and triglyceride, total cholesterol, low density lipoprotein (LDL), very low density lipoprotein (VLDL), elevated high density lipoprotein (HDL), body weight and hematological parameters were assessed in diabetic and normal rats. The extract doses used were 200 and $400 \mathrm{mg} / \mathrm{kg}$ body weight. Acute toxicity studies were also carried out

Results: In the extract doses, 200 and $400 \mathrm{mg} / \mathrm{kg}$, reduced blood glucose levels in a dose-dependant manner, from $168.0 \pm 18.5 \mathrm{mg} / \mathrm{dl}$ at $0 \mathrm{~h}$ to $43.0 \pm 9.3 \mathrm{mg} / \mathrm{dl}$ at the 12 th hour and from $146.50 \pm 22.1$ $\mathrm{mg} / \mathrm{dl}$ at $0 \mathrm{~h}$ to $37.250 \pm 6.3 \mathrm{mg} / \mathrm{dl}$ at the $12^{\text {th }}$ hour, respectively. Oral administration of $400 \mathrm{mg} / \mathrm{kg}$ of the extract for 21 days significantly reduced $(p<0.001)$ serum glucose, serum triglyceride, total cholesterol, low density lipoprotein, and very low density lipoprotein, but elevated $(p<0.05)$ high density lipoprotein in diabetic experimental rats, compared to diabetic control. The extract prevented a decrease in body weight in treated diabetic rats and promoted an improvement in haemoglobin levels. Total antioxidant activity assay revealed that $1 \mathrm{~g}$ of dry leaf powder was equivalent to $0.035 \mathrm{~g} / \mathrm{ml}$ of ascorbic acid. The extract showed no toxicity up to $2 \mathrm{~g} / \mathrm{kg}$ body weight.

Conclusions: This study shows that the aqueous extract of Amaranthus tricolor possesses some beneficial antidiabetic properties that warrant further research.
\end{abstract}

Keywords: Amaranthus tricolor, Anti-hyperglycemia, Anti-hyperlipidemia; Amaranthus, Antioxidant activity, Phosphomolybdenum 


\section{INTRODUCTION}

Diabetes mellitus is a syndrome initially characterized by loss of glucose homeostasis [1]. One of the main challenges in managing diabetes is maintaining blood glucose at near normal level with almost no episode of major fluctuation.

The status and duration of hyperglycemia decide the degree of damage to vital organs while improvement in diabetic status defers the onset and progression of diabetic insult to vital organs [2]. Anemia is commonly found in hyperglycemic patients and is associated with an increased risk of diabetic complications leading to nephropathy, retinopathy and macro vascular diseases [3].

Treatment of diabetes starts with the introduction of oral hypoglycemic agents, dietary restrictions coupled with exercise regimen and eventually administration of insulin in more severe cases. Most hypoglycemic agents have various serious side effects. Insulin therapy results in sudden bouts of hypoglycemia that needs constant monitoring. This has led to increased demand for antihyperglycemic agents with fewer or no side effects. Recent decades has witnessed a resurgent of interest in traditional plant treatments for diabetes [2]. The World Health Organization, has recommended that indigenous plants be used as alternative medicine in the management of diabetes mellitus, particularly in developing countries where safe modern drugs, health centers and resources are limited or lacking [4].

A. tricolor (Tambdi Bhaji/Lal Saag) is native to a large part of India and forms an integral part of the Goan staple diet. Its mild spinach like flavor, high nutritive value, ability to grow in hot weather and lower cost, have made it a very popular vegetable. The plant is well known for its purple betalain pigments, such as amaranthine and isoamaranthine [5]. An antiviral protein that imparts high resistance to sunnhemp rosette virus has been purified from the dried leaves of $A$. tricolor [6]. Three galactosyl diacylglycerols (1-3) with potent cyclooxygenase and human tumor cell growth inhibitory activities have also been isolated from the leaves and stems of $A$. tricolor [7]. Linolenic, palmitic acid and spinasterol are also reported to be present in the leaves of the plant [8].

Goan/Indian folklore suggests that the plant is a good liver tonic and therefore recommended as a vegetable for diabetic and anemic patients. The present study was conducted to evaluate the antidiabetic, hypolipidemic, hematological and antioxidant effects of Amaranthus tricolor on alloxanmediated diabetes in rats.

\section{EXPERIMENTAL}

\section{Plant material}

Fresh Amaranthus plants were collected in the month of February 2007 from a local source in Fatorda, Goa, India. The plant was identified by Dr. Janarthanam, Department of Botany, Goa University and a voucher specimen (GUBH-PVAC-0515) was deposited at the Botany Herbarium Unit of Goa University, Goa, India. The leaves were blended with cold distilled water for $3 \mathrm{~min}$ with solid: liquid ratios of $1: 3(\mathrm{AE} I)$ and 1:1.5 (AE II). In each case, the slurry was strained through a cheese cloth folded eight times to sieve out all fibers and yield the aqueous extract. The residue was severally milled and the filtrates combined. One milliliter of the extract was dried in an oven at $40{ }^{\circ} \mathrm{C}$ to constant weight to determine its yield.

\section{Qualitative and quantitative determination of phytoconstituents}

Qualitative determination of phytoconstituents of the extract was carried out using standard analytical procedures. Lipids were estimated using a Soxhlet apparatus with petroleum ether (b.p. $60-80{ }^{\circ} \mathrm{C}$ ) [9] as solvent. Quantitative determination of phytosterols was by the Libermann-Buchard method [10] using $\beta$-sitosterol $(1 \mathrm{mg} / \mathrm{ml})$ as standard. 
Polyphenol assay was carried out by FolinDenis method [11] using tannic acid (1 $\mathrm{mg} / \mathrm{ml}$ ) as standard. Assay of tannins was carried out by using a standard method [12].

\section{Animals}

Male Albino rats (Wt. 110 - $130 \mathrm{~g}$ ) were housed in standard polypropylene cages, allowed free access to water and standard pellet diet (Hindustan Lever, Bangalore, India), and maintained at room temperature $\left(25 \pm 2{ }^{\circ} \mathrm{C}\right)$ throughout the study. Ethical approval was obtained from the Institutional Animal Ethics Committee (ref no. 206/C 2007), based on the Committee for the Purpose of Control and Supervision of Experiments on Animals (CPCSEA) guidelines [13], which were followed throughout the study.

\section{Determination of $\mathrm{LD}_{50}$ and acute oral toxicity}

$\mathrm{LD}_{50}$ determination was carried out as per OECD guidelines using AOT425 software [14]. Single oral doses of the extract $(0.1-2$ $\mathrm{g} / \mathrm{kg}$ BW) were administrated to different groups of rats. The animals were observed continuously for the first $4 \mathrm{~h}$ and intermittently for the next 48 and $72 \mathrm{~h}$, following administration of the plant extract. The rats were observed for grooming, hyperactivity, sedation, respiratory rate, convulsion and reflexes.

\section{Experimental design}

Alloxan $(140 \mathrm{mg} / \mathrm{kg}$ BW) was administered intraperitoneally to the animals [15]. After 72 hours, rats with fasting blood glucose levels > $110 \mathrm{mg} / \mathrm{dl}$ were included in the study. The extracts were administered orally by gavage. Control groups were given distilled water equivalent to the volume of the extract administered. Treatments with plant extracts started $72 \mathrm{~h}$ after alloxan injection and establishment of hyperglycemia.

\section{Acute effects}

The control and alloxan-treated rats were divided into four groups of 6 rats each. Group I - normal, received distilled water; Group II diabetic, received distilled water; Group III diabetic, received $\mathrm{AE}$ I $(200 \mathrm{mg} / \mathrm{kg}$ BW) orally; and Group IV - diabetic, given AE II $(400 \mathrm{mg} / \mathrm{kg} \mathrm{BW})$ orally.

Blood glucose was estimated [15] using a glucometer (One Touch Horizon, Johnson \& Johnson) at $0,3,6,9$ and $12 \mathrm{~h}$ after administration of a single dose of the vehicle/extract.

\section{Chronic effects}

Based on the results of the acute tests, the more effective dose (400 mg/kg BW) was chosen for chronic treatment and was administered once a day for 21 days [15]. The rats $(\mathrm{N}=18)$ were divided into three groups of 6 rats each. Group I - normal, given distilled water orally; Group II - diabetic rats, given distilled water orally; Group III diabetic rats, given AE II (400 mg/kg BW). Body weight was taken on days $1,7,14$, and 21 of the experiment. Blood glucose levels, lipid profile and hematological parameters were estimated on day 21 of the experiment. All determinations were made in the preprandial state.

\section{Biochemical determinations}

After the last dose, animals were fasted for 12 hours and sacrificed under anesthesia. Blood was collected by cardiac puncture into clean sterile vials containing EDTA, for the study of hematological parameters. The remaining blood was collected in glass centrifuge tubes and allowed to clot in the fridge to facilitate serum separation. The separated serum was aspirated out into sterile centrifuge tubes and centrifuged at $3500 \mathrm{rpm}$ for $10 \mathrm{~min}$. Each serum sample was stored in duplicate in clean sterile micro centrifuge tubes at $-4^{\circ} \mathrm{C}$ until analysis. glucose, total cholesterol, triglycerides, HDL, 
LDL, and VLDL were assayed using commercially available kits (Crest Biosystems, Goa).

\section{Antioxidant activity}

Antioxidant activity of the water extract was measured by ferric reducing ability of plasma (FRAP) assay [16] and 2,2-diphenyl-1picrylhydrazyl (DPPH) assay [17]. Total antioxidant capacity was measured by phosphomolybdenum assay [17]. DPPH radical scavenging activity was calculated as (\% inhibition) according to Eq 1.

$$
\% \text { Inhibition }=\frac{100(C-5)}{C}
$$

where $\mathrm{C}$ and $\mathrm{S}$ are the absorbance of control and test sample, respectively, at $517 \mathrm{~nm}$.

FRAP activity was calculated according to Eq 2.

$$
\text { FRAPvalue }=\frac{\text { SaxFS }}{S t}
$$

where $\mathrm{Sa}$ and St are changes in the absorbance of the sample and standard, respectively, between 0 and $4^{\text {th }}$ min, and FS is the FRAP value of the standard.

\section{Statistical analysis}

The results obtained were expressed as mean \pm SD. Significant difference between groups were determined using Student $t$-test (Microsoft Office Excel 2003) and differences were considered significant at $p<0.05 ; p<$ 0.001 was considered highly significant.

\section{RESULTS}

The effects of acute and chronic treatments on the diabetic rats are presented in Figs 1 and 2, respectively. Alloxan treatment elevated blood glucose level beyond that found in controls indicating a diabetic state was achieved. The rats that received a single dose of either AE I (200 mg/kg) or AE II (400 $\mathrm{mg} / \mathrm{kg}$ ) exhibited significant reduction in blood glucose level by the 3rd hour. At the lower dose of the extract $(200 \mathrm{mg} / \mathrm{kg})$, steady reduction in blood glucose level was maintained between the 9th and 12th hour. However, the higher dose of the extract $(400 \mathrm{mg} / \mathrm{kg} \mathrm{BW})$ caused a more sustained reduction of blood glucose levels beyond the $9^{\text {th }}$ hour, further reduced by the 12th hour, a highly significant $(p<0.001)$ decrease in blood glucose level occurred at the end of 21 days. This suggests a prolonged antidiabetic effect by the extract (Fig. 2).

Serum cholesterol, triglyceride and LDL levels were significantly higher $(p<0.001)$ while HDL levels were significantly decreased $(p<0.05)$ in diabetic controls, compared to normal control. Following treatment of diabetic group with $A E$ II, a significant reduction $(p<0.001)$ in serum cholesterol, triglyceride and LDL and a significant increase $(p<0.05)$ in HDL were observed.

As Fig 3 shows, diabetic controls exhibited a significant decrease $(p<0.001)$ in body weight compared with normal controls. The diabetic animals given $400 \mathrm{mg} / \mathrm{kg}$ extract showed a lower weight loss, compared with the diabetic controls (Fig. 3 ).

Toxicity study revealed that none of the extract doses up to $2 \mathrm{~g} / \mathrm{kg}$ caused any visible symptoms of distress or toxicity In the rats, The effect of the $400 \mathrm{mg} / \mathrm{kg}$ extract dose on $\mathrm{Hb}, \mathrm{PCV}$, and RBC and WBC counts is presented in Table 1. The diabetic controls showed a highly significant $(p<0.001)$ decrease in $\mathrm{Hb}$ level, PCV, and RBC and WBC counts, compared with normal control. On the other hand, the extract increased significantly $(p<0.05) \mathrm{Hb}$ level in the diabetic group, compared to control. However, rise in WBC and RBC counts was negligible in the extract-treated group, compared to diabetic control, but PCV increased significantly $(p<$ $0.05)$. The normal control group that received the extract showed a decrease $(p<0.05)$ in WBC count, compared to the normal control. 


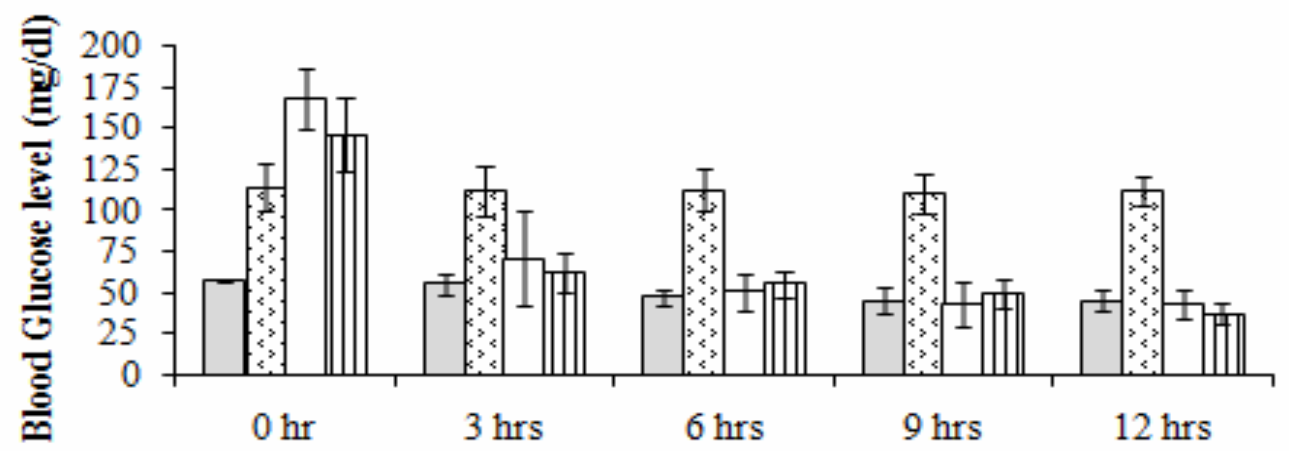

Fig 1: Dose dependant reduction of hyperglycemia by $A$. tricolor extract. Note: $\quad$ = normal; " $" ;$; = diabetic; $\sqcup=$ diabetic $+200 \mathrm{mg}$ dose extract dose; $I I I I=$ diabetic $+400 \mathrm{mg}$ dose extract dose

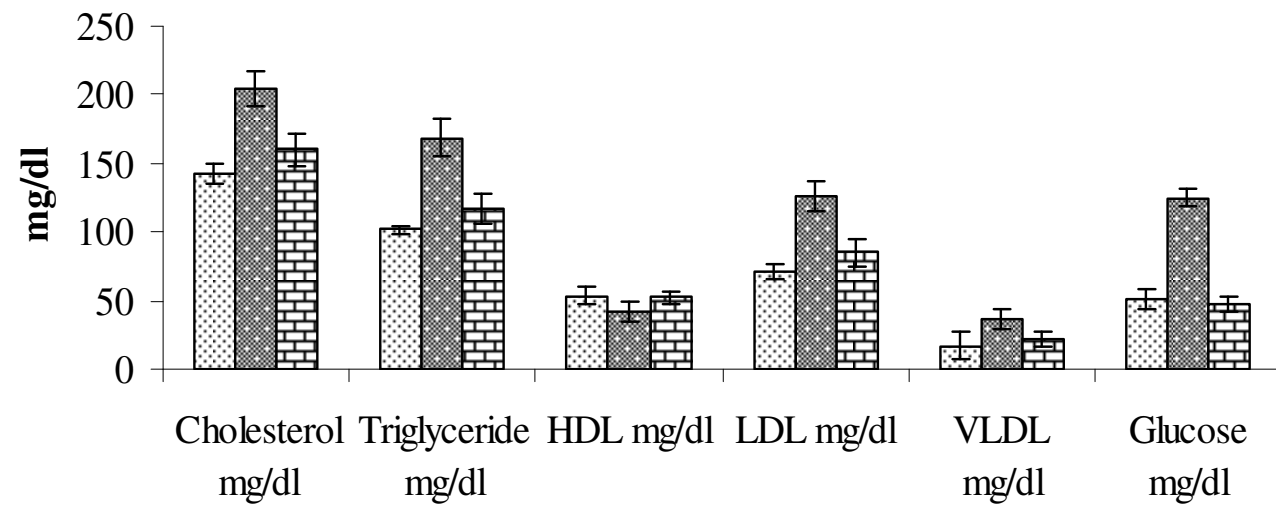

Fig 2: Effect of treatment of $A$. tricolor on glucose and lipid profile. Note: 1 = normal; $:$; diabetic $+400 \mathrm{mg}$ dose extract dose

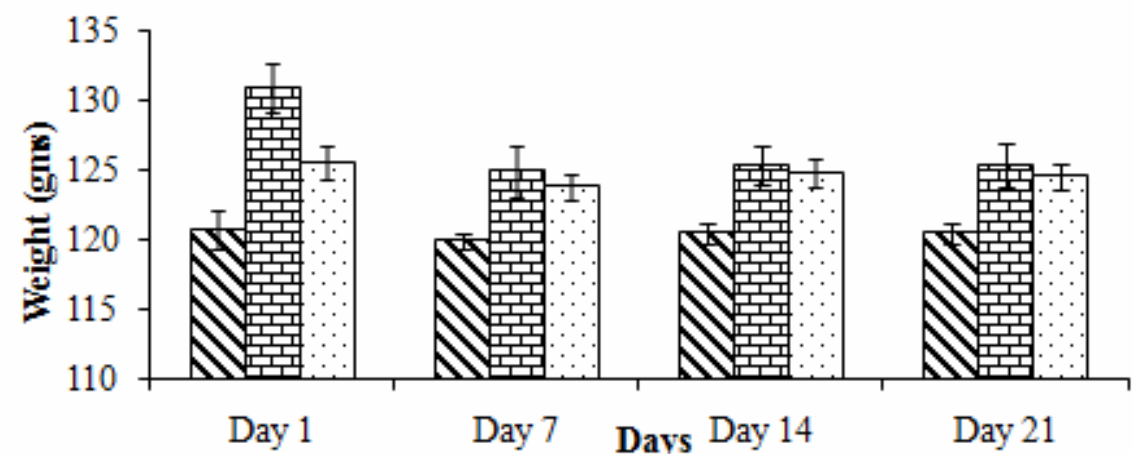

Fig 3: Effect of $A$. tricolor on body weights of normal and treated rats. Note: $\mathbf{N}=$ normal; 午; = diabetic; $=$ diabetic $+400 \mathrm{mg}$ dose extract dose 
Table 1: Effect of $A$. tricolor on the hematological values in normal and diabetic rats

\begin{tabular}{|c|c|c|c|}
\hline Parameter & Normal & Diabetic & $\begin{array}{c}\text { Diabetic + } \\
\text { Extract }^{\star}\end{array}$ \\
\hline $\begin{array}{l}\text { WBC (x } \\
\left.10^{3} / \mu \mathrm{L}\right)\end{array}$ & $\begin{array}{c}5.38 \pm \\
0.47\end{array}$ & $\begin{array}{l}3.12+\frac{+}{5} \\
0.16^{\frac{b}{6}}\end{array}$ & $3.36 \pm 0.27$ \\
\hline $\begin{array}{l}\text { RBC (x } \\
\left.10^{6} / \mu \mathrm{L}\right)\end{array}$ & $\begin{array}{l}5.6 \pm \\
0.34\end{array}$ & $\begin{array}{l}4.36+ \\
0.49^{\frac{1}{b}}\end{array}$ & $4.78 \pm 0.71$ \\
\hline PCV (\%) & $\begin{array}{c}38.40 \pm \\
2.33\end{array}$ & $\begin{array}{c}33.85 \pm \\
2.85^{\mathrm{a}}\end{array}$ & $37.58_{\mathrm{y}} \pm 1.78$ \\
\hline $\mathrm{Hb}(\mathrm{g} / \mathrm{dl})$ & $\begin{array}{l}12 \pm \\
0.71\end{array}$ & $\begin{array}{l}9.54+\frac{+}{0} \\
0.97^{\frac{b}{5}}\end{array}$ & $10.96 \pm 0.90$ \\
\hline
\end{tabular}

$a=p \leq 0.05, b=\leq 0.001$ when compared to normal; $y=$ $p \leq 0.05, z=\leq 0.001$ when compared to diabetic

The results of phytochemical analysis (Table 2) indicate the presence of tannins and phenols in the aqueous extract. The major phytoconstituents detected in $1 \mathrm{~g}$ of dry sample of $A$. tricolor extract were lipids $(2.00$ $\%)$, polyphenols $(1.56 \%)$, tannins $(1.25 \%)$ and phytosterols $(0.18 \%)$.

Table 2: Some phytoconstituents present in the leaf extract of $A$. tricolor

\begin{tabular}{ll}
\hline Phytoconstituent & \multicolumn{1}{c}{ Content (\%w/w) } \\
\hline Lipid & 2.0 \\
Phytosterols & 0.178 \\
Polyphenols & 1.561 \\
Antioxidants & $0.035 \mathrm{~g} / \mathrm{ml}^{\star}$ \\
Tannins & 1.25 \\
\hline${ }^{*}$ Equivalent to ascorbic acid
\end{tabular}

Data obtained on total antioxidant activity revealed that $1 \mathrm{~g}$ of dry leaf powder was equivalent to $0.035 \mathrm{~g} / \mathrm{ml}$ of ascorbic acid, while the free radical scavenging activity of the aqueous extract was almost comparable with standard butylated hydroxy toluene (BHT). FRAP data confirmed that the aqueous extract had very high free radical scavenging activity.

The free radical scavenging activity of the extract of obtained by DPPH assay is comparable to the standard butylated hydroxy toluene (BHT), with the aqueous extract exhibiting an inhibition of $65.0 \%$ at 30 min, compared with the standard BHT inhibition value of $78.1 \%$. The antioxidant capacity of the aqueous extract, measured by ferric reducing ability (FRAP) assay, was much higher $(14.26 \mathrm{mM} / \mathrm{L})$, compared with $\mathrm{FeSO}_{4}$ standard (2mM/L).

\section{DISCUSSION}

Alloxan induces diabetes mellitus by disrupting the balance between cellular antioxidant defenses and free radical formation as well as by partially destroying $\beta$ cells in the pancreas [18]. Diabetes-induced hyperlipidemia is attributable to excess mobilization of fat from adipose tissue due to underutilization of glucose [19].

Amaranthus tricolor is traditionally used in folk medicine as a general tonic, to improve immunity vis a viz overall health improvement. The present study shows that A. tricolor is not only a hypoglycemic but also a weight-enhancing agent. Normally, diabetic animals and patients exhibit a decrease in body weight, due to loss of fluid from the body or loss of tissue mass. On treatment with the extract, the weight remained almost constant in the diabetic experimental group.

Administration of the aqueous extract of $A$. tricolor, to diabetic rats, significantly reduced cholesterol, triglyceride \& LDL level, and increased HDL level. Tannic acid, a major component of tannins, has the capacity to decrease blood glucose level, by stimulating glucose transport, while inhibiting adipogenesis [20]. Various studies have shown that phytosterols and polyphenols have the potential to reduce hyperlipidemic conditions and blood glucose level [8]. Therefore, reduction in blood glucose and blood lipid levels in the diabetic rats can be attributed to the action of the phytosterols, polyphenols and tannins present in A. tricolor. The presence of antioxidants in $A$. tricolor can mitigate damage to the insulin-producing $\beta$ cells of pancreas. The differential blood count showed decrease in WBC in the extract-fed normal rats. Tannin may be responsible for cell lyses of WBCs as tannin is known to cause cell lysis [21]; however, 
there is need to investigate further whether tannin selectively promotes lysis of WBCs.

In diabetes mellitus, additional factors may contribute to anemia, such as increased hemolysis due to advanced glycosylation end-products (AGE) on the RBC membranes or iron and vitamin B12 deficiencies [22]. Recent studies have shown that anemia is a key indicator of early impairment of organ functions in diabetic patients and if left untreated, can cause significant renal and cardiac damage [23] resulting ultimately in death. AE II-treated rats showed significant increase in $\mathrm{Hb}$ concentration, which could be partly attributed to its high iron content [24], suggesting $A$. tricolor's antianaemic properties.

The aqueous extract analysis showed the presence of tannins and phenols, which together constitute the polyphenolic group. Polyphenols are known to have antioxidant, antidiabetic, antihypertensive, hypolipidemic, anticancer and antimicrobial activities. Therefore, the antidiabetic activity may be due to the polyphenol group.

The test plant extract showed high free radical scavenging activity, indicating its potential in arresting cellular damage. In the last decade, interest in the antioxidant activity of plant extracts has grown considerably due to the knowledge that free radicals responsible for onset and aggravation of ailments can be quenched by antioxidants of plant origin. Antioxidants, due to their radical scavenging activity, are useful for the management of those ailments.

The oral safety dosage of the extract using Acute Oral Toxicity Program (AOT 425) guidelines was greater than $2000 \mathrm{mg} / \mathrm{kg}$ body weight. Any compound with an oral $L_{50}>$ $1000 \mathrm{mg} / \mathrm{kg}$ can be considered a low toxicity and safe agent [25]. Since the administration of the aqueous extract of $A$. tricolor resulted in a significant reduction in blood glucose level and an increase in haemoglobin, we conclude that this plant is a potential natural source of an agent for antidiabetic, hypolipidemic and blood tonic. Though, the plant has been used traditionally as a general tonic and good natural source of iron, it should be consumed with caution, as this study shows that it has a tendency to induce reduction in WBC count.

\section{CONCLUSION}

The current study shows that $A$. tricolor may be useful in the management of hyperglycemia and associated lipidemia. The mechanisms of action of this plant extract on the hyperglycemic state and its related complications need to be studied further. The plant may also find use as a prospective food supplement and for the management of the overall health status of diabetic patients. Furthermore, $A$. tricolor appear to be a potential natural source of ingredients for the management antidiabetic, antihyperlipidemic and antioxidants

\section{ACKNOWLEDGEMENT}

This publication is part of an ongoing $\mathrm{PhD}$ work supported by the University Grants Commission, New Delhi, India, under the UGC-RFMS scheme.

\section{REFERENCES}

1. Wolff SP. Diabetes mellitus and free radicals: Free radicals, transition metals and oxidative stress in the aetiology of diabetes mellitus and complications. Br Med Bull 1993; 49: 642-652.

2. Day C. Traditional plant treatments for diabetes mellitus: pharmaceutical foods. Br J Nutr 1998; 80: 5-6.

3. Thomas MC, Maclsaac RJ, Tsalamandris C, Molyneaux L, Goubina I, Fulcher G, Yue D, Jerums $G$. The burden of anaemia in type 2 diabetes and the role of nephropathy: a crosssectional audit. Nephrol Dial Transpl 2004;19: 1792-1797.

4. W.H.O. Launches of the first global strategy on the traditional medicine- Press release. WHO, Geneva, 2002; 38: 2.

5. Jerz G, Arrey TN, Wray V, Du Q, Winterhalter $P$. Structural characterization of 132- hydroxy(132- S) - phaeophytin - a from leaves and stems of Amaranthus tricolor isolated by high- 
speed countercurrent chromatography. Innovat Food Sci Emerg Tech 2007; 8(3): 413-418.

6. Roy S, Sadhana P, Begum M, Kumar S, Lodha ML, Kapoor HC. Purification, characterization and cloning of antiviral/ribosome inactivating protein from Amaranthus tricolor leaves. Phytochemistry. 2006; 67(17): 1865-1867.

7. Jayaprakasam B, Zhang $Y$, Nair MG. Tumor cell proliferation and cyclooxygenase enzyme inhibitory compounds in Amaranthus tricolor. $J$ Agric Food Chem 2004; 52(23): 6939-6943.

8. Harborne JB. Phytochemical methods- A guide to modern techniques of plant analysis. London / New York: Chapman and Hall, 1984.

9. AOAC. Official Methods of Analysis. 15th edn. Washington, DC: Association of Official Analytical Chemists, 1996.

10. Shahidi F. Extraction and Measurement of Total Lipids, Curr Protoc Food Analyt Chem. John Wiley \& Sons, Inc. 2001; D1.1.1-D1.1.11.

11. Schanderl, $S$ H. Method in Food Analysis. Academic Press, New York, 1970.

12. W.H. O. Quality control methods for medicinal plant materials. WHO, Geneva, 1998; 13:44.

13. CPCSEA. CPCSEA Guidelines for laboratory animal facility, Indian J Pharmacol 2003; 35 (4): $257-274$

14. OECD. Guidelines for the testing of chemicals revised draft guideline 425: Acute Oral Toxicity - Up and Down Procedure (UDP). Paris: OECD Publishing, 2006.

15. Nagappa AN, Thakurdesai $P A$, Rao NV, Singh J. Antidiabetic activity of Terminalia catappa Linn fruits. J Ethnopharmacol 2003; 88: 45-50.

16. Benzie IFF, Strain JJ. Ferric reducing ability of plasma (FRAP) as a measure of antioxidant power: The FRAP assay. Anal Biochem 1996; 239: 70-76.

17. Wang $K$, Pan Y, Wang $H$, Zhag $Y$, Lei Q, Zhu Z, Li $H$, Liang $M$. Antioxidant activities of Liquidambar formosa Hance leaf extracts. Med Chem Res 2009; 19(2): 166-176.

18. Szkudelski T. The mechanism of alloxan and streptozotocin action in $B$ cells of the rat pancreas. Physiol Res 2001; 50: 536-546.

19. Jeyanthi K, Christy MV. Hypolipidemic effect of Citrullus colocynthis seed powder in alloxan induced diabetic rats. J Int Dent Med Res 2009; 2(3): 105-109.

20. Xueqing $L$, Jae-kyung $K$, Yunsheng $L$, Jing $L$, Fang $L$, Xiaozhuo C. Tannic acid stimulates glucose transport and inhibits adipocyte differentiation in 3T3-L1 cells. J Nutr 2005; 135: 165-171.

21. Toffazal Mdl, Toshiaki I, Mitsuyoshi S, Satoshi T. Zoosporicidal activity of polyflavonoid tannin identified in Lannea coromandelica stem bark against phytopathogenic oomycete Aphanomyces Cochlioides. I Agric Food Chem 2002; 50(23): 6697-703.

22. Donnelly S. New insights into renal anemia. Can J Diabetes 2003; 27(2): 176-181.

23. O'Connell N. Anaemia: a silent complication of diabetes; later management. Diabetes Voice 2003; 48: 25-27.

24. Rangarajan A, Chenoweth WA, Kelly JF, Agee KM. Iron bioavailability from amaranthus species: 2 - Evaluation using haemoglobin repletion in anaemic rats. J Sci Food Agric 1998; 78: 274280.

25. Clarke EGC, Clarke ML. Veterinary toxicology. Cassel and Collier Macmillan Publishers, London, 1977; pp 268-277. 